\title{
The Effect of Aluminium Surface Treatments on the Bonding Properties of Silica-Modified Epoxy Adhesive Joints: A Statistical Approach
}

\author{
Francisco M. Dos Santos ${ }^{1}$, Lívia A. de Oliveira ${ }^{1,2}$, Alysson H. S. Bueno ${ }^{1,2}$, Rodrigo T. S. \\ Freire $^{1,2}$, Leandro José da Silva ${ }^{1,2}$, Gilberto García del Pino ${ }^{3}$ and Tulio H. Panzera ${ }^{1,2,{ }^{*}}$ \\ ${ }^{1}$ Centre for Innovation and Technology in Composite Materials - ClT C, Department of Mechanical \\ Engineering, Federal University of São João Del-Rei, Brazil \\ ${ }^{2}$ Department of Natural Sciences, Federal University of São João Del-Rei, Brazil \\ ${ }^{3}$ Department of Mechanical Engineering, State University of Amazonas (UEA), Manaus, Brazil
}

\begin{abstract}
A full factorial design is carried out to investigate the effects of different surface treatments, the inclusion of silica microparticles and the use of wash primer on the apparent shear strength and adherent strength of single-lap aluminium joints. Scanning electron microscopy, surface energy and roughness measurements are performed to characterise the aluminium surface. The results show that the use of wash primer decreases the apparent shear strength of the joints significantly. The cohesive failure of the primer is the main cause of the reduction in strength. On the other hand, the inclusion of 10 wt.\% of silica microparticles in the adhesive layers increases the shear strength by $26 \%$. Surfaces treated with $\mathrm{NaOH}$ for one minute, without using a wash primer, result in the most resistant joint. In contrast to the apparent shear strength, adherent strength is most effective when only degreasing is considered.
\end{abstract}

Keywords: Aluminium surface treatment, silica microparticles, apparent shear strength, adherent strength, full factorial design (DoE).

\section{INTRODUCTION}

Aluminium is commonly used by numerous transportation industries for its well-known performance, durability, lightweight and costeffectiveness. However, the surface of aluminium alloys contains a natural oxide layer that provides low bonding capacity $[1,2]$. Surface treatments, such as mechanical abrasion and alkaline etching, have been used extensively to remove this natural layer and provide a more homogeneous surface, increasing its bonding strength $[3,4]$.

Two types of connections, i.e., adhesive and mechanical, are widely adopted to join structural aluminium components. Adhesive joints have attracted attention due to their characteristics such as lower structural weight, uniform stress and load distribution, high resistance to fatigue and good appearance, while the conventional mechanical connection, represented by fasteners and rivets, causes stress concentrations and premature failure [5-8].

*Address correspondence to this author at the Centre for Innovation and Technology in Composite Materials $-\mathrm{CIT}^{\mathrm{e}} \mathrm{C}$, Department of Mechanical Engineering, Federal University of São João Del-Rei, Brazil;

Tel/Fax: +553233795879; E-mail: panzera@ufsj.edu.br
The performance of the adhesive connections has been evaluated through mechanical tests, carried out on different types of joints, such as single-lap joint (SLJ) [9], double-lap joint (DLJ) [10], strap joint (SJ) [11], double-strap joint (DSJ) [12], scarf joint (ScJ) [13], single-L joint [14], T-joint [15] and T-peel joint [16]. Among them, the single lap is the most used joint due to ease of fabrication and lack of specific manufacturing skills [17].

Two techniques have been used to improve the adhesive bonding to the adherent: the use of (i) primers on the substrate surface and (ii) dispersed fillers in the adhesive polymer $[18,19]$. Low-viscosity wash primers generally increase the shear strength of the joint as a result of better-filled aluminium surfaces attributed to a larger interface area between the adhesive and the primer. In addition, wash primers have corrosioninhibiting additives that further enhance the chances of providing long-term bonding strength in harsh environment $[20,21]$. On the other hand, the incorporation of silica micro or nanosized particles in adhesives is a simple, cost-effective and reliable method to increase bonding capabilities between adhesives and adherents [22].

Although there is a substantial amount of research on chemical surface treatments, application of primer and incorporation of ceramic microparticles on

(c) 2021 Lifescience Global 
aluminium surfaces, this work combines the three methods considering a statistical analysis. A design of experiment (DoE) is conducted to investigate the effect of surface treatment (degreasing, mechanical abrasion and alkaline etching), the use of primer (with and without) and the inclusion of silica microparticles ( 0 and $10 \mathrm{wt} . \%)$ on the adhesive properties of single-lap joints made of aluminium alloy. The treated surfaces are evaluated through microscopy, roughness, contact angle and surface energy. The mechanical responses investigated in the single-lap test are the apparent shear strength and the adherent strength.

\section{MATERIALS AND METHODS}

\subsection{Materials}

Type AA-1200 aluminium sheets $0.5 \mathrm{~mm}$ thick are supplied by Belmetal (Brazil). The polymeric adhesive used is the epoxy Renlam M-1 and the HY956 hardener, both supplied by Huntsman ${ }^{\circledR}$. The wash primer (bicomponent: 045/051) is supplied by SherwinWilliams ${ }^{\circledR}$. The quartz silica particles are supplied by Moinhos Gerais Company (Brazil) and are classified by sieving in a size range of 325 - 400 US-Tyler (37 $\mu \mathrm{m}$ and $44 \mu \mathrm{m})$.

\subsection{Surface Treatment}

Initially, the $178 \times 103 \mathrm{~mm}^{2}$ aluminium rectangular plates are cut following the recommendations of ASTM D1002 [23]. Subsequently, the aluminium plates are washed in running water with neutral detergent and then paper wiped with acetone to remove the remaining grease and oil. Degreasing is effective in removing contaminants from the surface and this process is normally used as a reference condition. However, this procedure does not provide acceptable surface conditions for adhesive bonding and appropriate additional treatments are required [24].

Three different surface treatments are conducted in this experiment. The first is mechanical abrasion using sandpaper (grit 600) followed by cleaning with acetone. The second and third treatments are alkaline cleaning by immersing the plates for 1 and 5 minutes, respectively, in a solution of $100 \mathrm{~g} / \mathrm{l}$ of $\mathrm{NaOH}$ at $60^{\circ} \mathrm{C}$, followed by desmutting process in a $50 \%(\mathrm{v} / \mathrm{v})$ nitric acid solution for 30 seconds at room temperature $\left(\sim 23^{\circ} \mathrm{C}\right)$. After the treatments, the plates are rinsed with tap water followed by hot blow-drying.

\subsection{Statistical Analysis}

A Full Factorial Design $4^{1} 2^{2}$, shown in Table 1, is established to investigate the effect of factors and levels on the response-variables, resulting in 16 conditions. The factors and levels analysed are the surface treatment (degreased, mechanical abrasion, alkaline cleaning for 1 and 5 minutes), the use of wash primer (with and without) and the inclusion of silica microparticles in the adhesive layers (0 and $10 \mathrm{wt} \%$ ). Two replicates and five specimens per condition are used in the experiment, totaling 160 single-lap

Table 1: Experimental Conditions

\begin{tabular}{|c|c|c|c|}
\hline Condition & Surface treatment & Wash primer & Silica inclusion (wt\%) \\
\hline \hline 1 & Degreased & With & 10 \\
\hline 2 & Degreased & With & 0 \\
\hline 3 & Degreased & Without & 10 \\
\hline 4 & Degreased & With & 10 \\
\hline 5 & Mechanical Abrasion & With & 0 \\
\hline 6 & Mechanical Abrasion & Without & 10 \\
\hline 7 & Mechanical Abrasion & Without & 0 \\
\hline 8 & Mechanical Abrasion & With & 10 \\
\hline 9 & $\mathrm{NaOH} 1$ min & With & 0 \\
\hline 10 & $\mathrm{NaOH}$ 1 min & Without & 10 \\
\hline 11 & $\mathrm{NaOH} 1$ min & Without & 0 \\
\hline 12 & $\mathrm{NaOH} 1$ min & With & 10 \\
\hline 13 & $\mathrm{NaOH} 5$ min & With & 0 \\
\hline 14 & $\mathrm{NaOH} 5$ min & Without & 10 \\
\hline 15 & $\mathrm{NaOH} 5$ min & Without & \\
\hline
\end{tabular}


Table 2: Surface Energy Components for the Probe Liquids [24]

\begin{tabular}{|c|c|c|c|}
\hline Probe liquids & Polar component $\left(\mathbf{m J} / \mathbf{m}^{2}\right)$ & Dispersive component $\left(\mathbf{m} J / \mathbf{m}^{2}\right)$ & Surface energy $\left(\mathbf{m J} / \mathbf{m}^{2}\right)$ \\
\hline \hline Water & 51.0 & 21.8 & 72.8 \\
\hline Ethylene Glycol & 19.0 & 29.3 & 48.3 \\
\hline
\end{tabular}

specimens. The data is manipulated in Minitab® software (v.18) using the Design of Experiment (DoE) and Analysis of Variance (ANOVA) techniques.

\subsection{Fabrication Process}

After the surface treatment (section 2.2), the plates are coated with wash primer, according to the experimental condition shown in Table 2. Primers play an important role in protecting the aluminium substrate prior to bonding [18]. The wash primer is applied using a spray gun to the edges of the aluminium surfaces (Figure 1a) in an area of at least ten times the size of the overlapping joint and a flow rate of $50 \mathrm{~mL} / \mathrm{min}$. The curing time of the primer is 4 hours at room temperature $\left(\sim 23^{\circ} \mathrm{C}, 55 \% \mathrm{RH}\right)$.

Before the manufacture of single-lap specimens, the epoxy system is prepared by mixing 5 parts of Renlam $M$ resin with 1 part of HY956 hardener. When the silica microparticles (10 wt.\%) are incorporated, they are first hand-mixed with the resin by 5 minutes, and then the hardener is added. The fabrication of single-lap specimens is accomplished by overlapping two coated plates in an area of $180 \times 5 \mathrm{~mm}^{2}$ with subsequent uniaxial compaction of $30 \mathrm{~N}$ for 24 hours, as shown in Figure 1b. A curing time of 7 days at room temperature $\left(\sim 23^{\circ} \mathrm{C}, 55 \% \mathrm{RH}\right)$ is considered based on the recommendations of the polymer technical datasheet. After curing, the plates are cut into seven specimens $25.4 \mathrm{~mm}$ wide. Two edge-specimens are discarded due to possible adhesive failure, resulting in five specimens (Figure 1c), as recommended by ASTM D1002 [23].

\subsection{Characterisation}

\subsubsection{Surface Morphologies}

Scanning electron microscopy (SEM) model Hitachi TM-3000 equipped with energy dispersive spectroscopy (EDS) model Quantax 70 is used to analyse the treated surfaces and the size of the adhesive layer. The surface roughness $(R a)$ of the treated surfaces is measured using a Form Talysurf 50 profilometer (Taylor Honson ${ }^{\circledR}$ ). The contact angle $(\theta)$ is measured with an Easyover 800x optical microscope using drops of water and ethylene glycol $(35 \mu \mathrm{l})$ as probe liquids at room temperature $\left(\sim 23^{\circ} \mathrm{C}, 65 \% \mathrm{RH}\right)$. The surface energy of the treated surfaces is calculated based on the surface energy components for the probe liquids, as shown in Table 2. The work of adhesion $\left(W_{a}\right)$ is calculated according to Equation 1, then the Young's equation (Eq. 2) is used to obtain Equation 3, where $\gamma_{S V}, \gamma_{L V}, \gamma_{S L}$ are the surface energies of the substrate, the liquid and the substrate/liquid interface, respectively [24].

$$
\begin{aligned}
& W_{a}=\gamma_{S V}+\gamma_{L V}-\gamma_{S L} \\
& \gamma_{S V}=\gamma_{S L}+\gamma_{L V} \cos \theta \\
& W_{a}=\gamma_{L V}(1+\cos \theta)
\end{aligned}
$$

The work of adhesion includes the polar and the dispersive components (Eq. 4), where $\gamma_{S V}^{p}$ and $\gamma_{L V}^{p}$ are

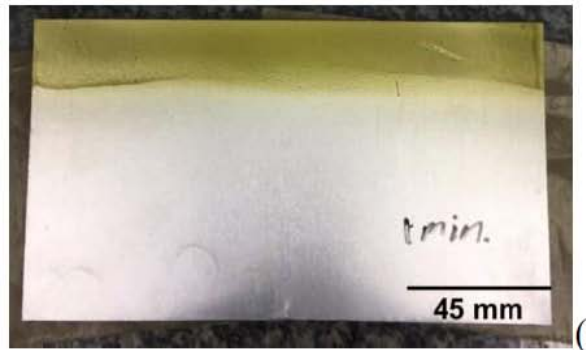

(a)

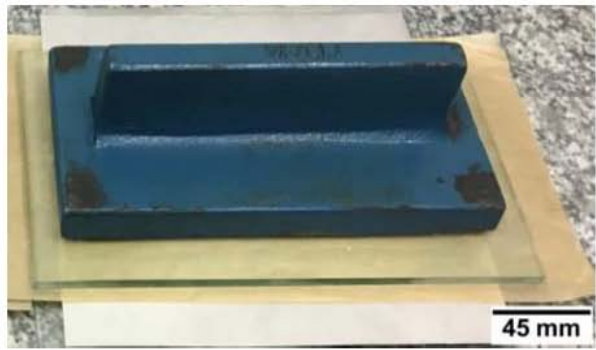

(b)

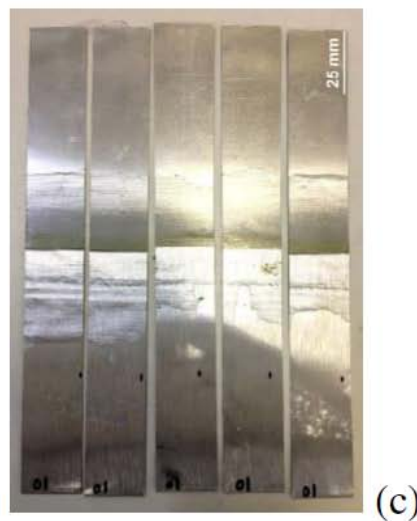

Figure 1: Plate with wash primer layer (a), joint fabrication via uniaxial compaction (b) and single-lap specimens (c). 
the polar components of the solid and the liquid surface energies, respectively, while $\gamma_{S V}^{d}$ and $\gamma_{L V}^{d}$ are the dispersive components of the solid and the liquid surface energies, respectively. In a system with two equations, one for water and another for ethylene glycol, Equation 4 is used to calculate the polar and dispersive components of the aluminium (solid) surface.

$W_{a}=2 \sqrt{\gamma_{S V}^{p} \gamma_{L V}^{p}}+2 \sqrt{\gamma_{S V}^{d} \gamma_{L V}^{d}}$

Equating the work of adhesion $\left(\mathrm{W}_{\mathrm{a}}\right)$ of Equations 3 and 4 , the total apparent surface energy of aluminium is obtained in Equation 5, as described by $\mathrm{Xu}$ et al. [24].

$\gamma_{S V}=\gamma_{S V}^{p}+\gamma_{L V}^{d}$

\subsubsection{Mechanical Characterisation}

The single lap joint specimens are tested under tensile efforts on a Shimadzu AG-X Plus testing machine, at a crosshead rate of $1.3 \mathrm{~mm} / \mathrm{min}$, as recommended by the ASTM D1002-10 [23]. Tabs are used during the test to keep the specimen aligned, as shown in Figure 2. The investigated responses are the apparent shear strength and the adherent strength. The apparent shear strength is calculated as the maximum load divided by the bonding area, while the adherent strength is calculated based on the slope of the load versus displacement curves $[19,25]$.

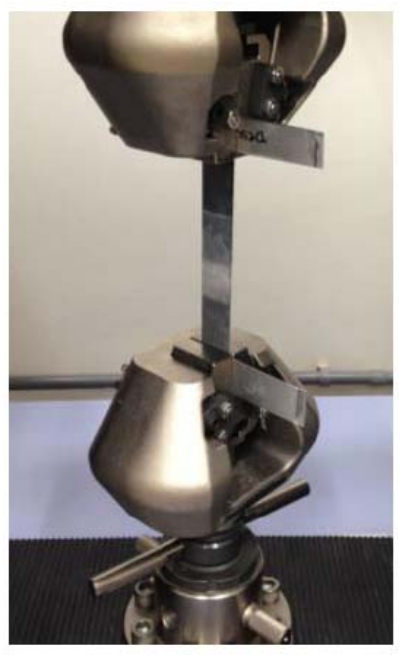

Figure 2: Single lap joint test.

\section{RESULTS AND DISCUSSION}

\subsection{Surface Morphology}

Figure 3 shows the backscattered electron images (BEI) of the aluminium surfaces and Table 3 shows the
EDS analysis of these surfaces. Figure $\mathbf{3 a}$ reveals that degreasing is not effective in removing all contaminants from the aluminium surface, as indicated by EDS (Table 3) which exhibits a greater content of carbon and oxygen in this region when compared to the alkaline treatment. The surface treated with mechanical abrasion has typical grooves caused by sandpaper (Figure 3b) and, consequently, a reduction in the percentage of aluminium, as shown in Table 3 . Mechanical abrasion increases the surface roughness and the contact area with the adhesive, promoting enhanced mechanical interlocking and shear strength. The aluminium surfaces etched with sodium hydroxide show typical pits (black dots in Figures $\mathbf{3 c}$ and $\mathbf{3 d}$ ) generated by the alkaline solution. It can be noted that the number of pits in the sample treated for 5 minutes (Figure 3d) is greater than those treated for 1 minute, attributed to the longer immersion time in the alkaline solution. In addition, sodium hydroxide causes a reduction in the percentage of carbon and oxygen due to the removal of the oxide layer, revealing intermetallic particles such as magnesium and iron, as shown by the small white dots in Figures $\mathbf{3 c}$ and $\mathbf{3 d}$.

Figure 4 shows the contact angles of the probe liquids for the different treatments on the aluminium surfaces. The calculated surface energies and roughness $(R a)$ are shown in Table 4 . The smaller the drop contact angle, the greater the surface energy, indicating a good surface wettability, which leads to increased adhesive properties [26]. Therefore, the surface treated with an alkaline solution for 5 minutes has the lowest contact angle in both water $\left(64.34^{\circ}\right)$ and ethylene glycol $\left(39.13^{\circ}\right)$ and the highest surface energy $\left(38.70 \mathrm{~mJ} / \mathrm{m}^{2}\right)$. On the other hand, the surface treated with mechanical abrasion presents greater roughness (501.9 nm).

Figure 5 shows the SEM image of the thickness layer of the adhesive in the joint, revealing an average value of $0.126 \mathrm{~mm}$.

\subsection{Statistical Analysis}

Tables 5 and $\mathbf{6}$ show the descriptive statistics for the apparent shear and adherent strength, respectively, for replicates 1 and 2 . The mean apparent shear strength data range from 2.22 to $7.83 \mathrm{MPa}$, and the mean adherent strength data range from 1395.9 to $4022.96 \mathrm{~N} / \mathrm{mm}$.

Table 7 shows the Analysis of Variance (ANOVA) for the mean apparent shear strength and the adherent 

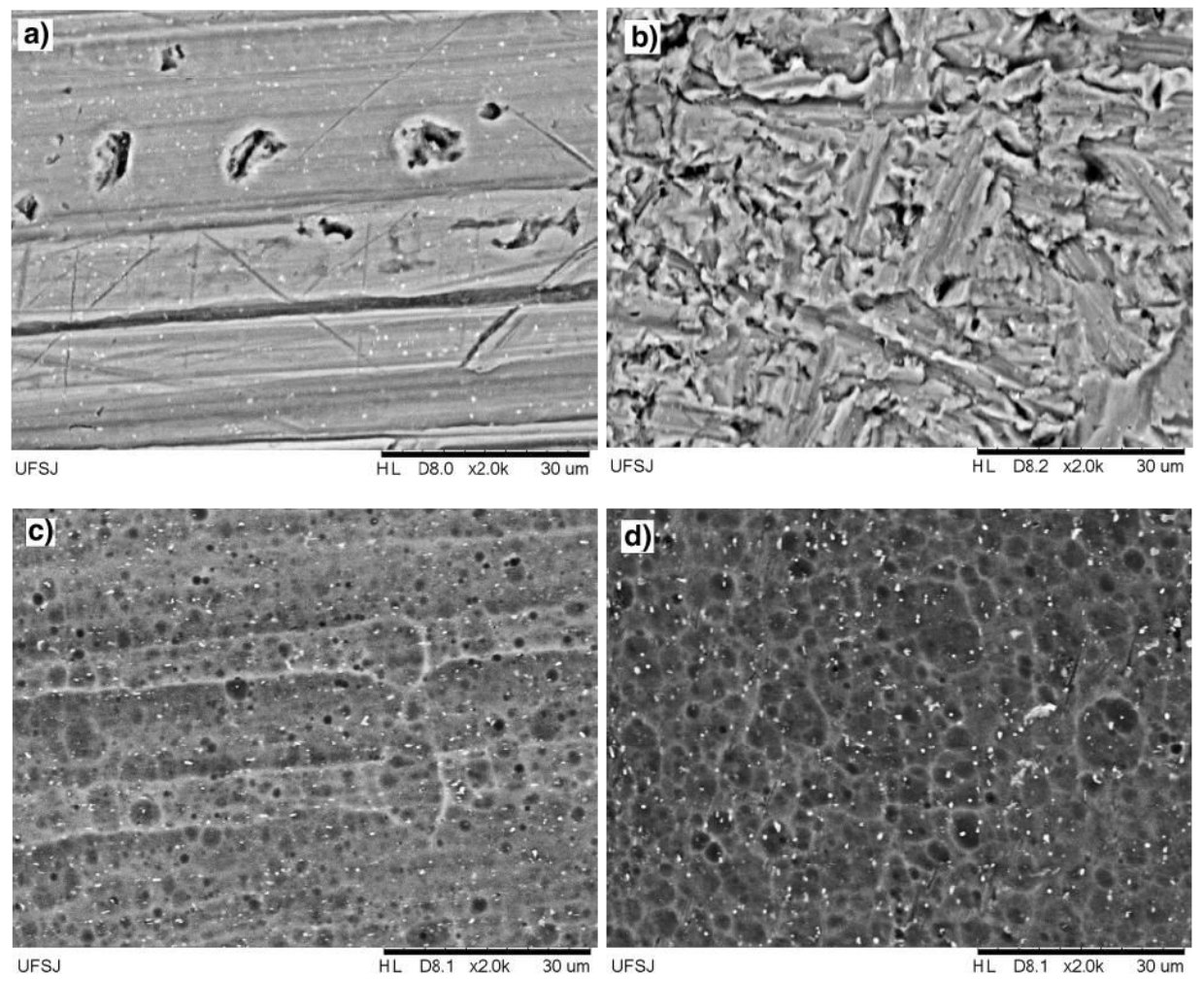

Figure 3: SEM images of aluminium surfaces treated by degreasing (a), mechanical abrasion (b), $\mathrm{NaOH}$ for $1 \mathrm{~min}(\mathbf{c})$ and $\mathrm{NaOH}$ for $5 \min (d)$.

Table 3: Composition of the Treated Aluminium Surfaces Obtained from EDS

\begin{tabular}{|c|c|c|c|c|c|}
\hline Element (wt.\%) & Al & C & 0 & $\mathrm{Fe}$ & Mg \\
\hline Degreased & 92.78 & 4.76 & 1.81 & 0.10 & 0.11 \\
\hline $\mathrm{NaOH}$ for $1 \mathrm{~min}$ & 94.48 & 3.65 & 0.97 & 0.28 & 0.62 \\
\hline $\mathrm{NaOH}$ for $5 \mathrm{~min}$ & 94.44 & 4.04 & 0.77 & 0.43 & 0.32 \\
\hline
\end{tabular}

strength. P-values less than or equal to an $\alpha$-level of 0.05 imply the significance of the factor and/or interaction effect on the response variable with a $95 \%$ confidence interval [27]. Significant effects will be interpreted via effect plots. F-values describe the ratio of two variances or, technically, two mean squares, which demonstrate the contribution of the factor or interaction effect. The wash primer is the main contributing factor on the response for the mean shear strength, revealing an F-value of 71.91 . The surface treatment is the main contributing factor on the response for the mean adherent strength, revealing an F-value of 35.61 .

$\mathrm{R}^{2}$ value indicates whether the statistical model behaves properly. This means that the variance of the properties is explained by the variance of the factors analysed. The closer to $1(100 \%)$ is the $R^{2}$, the better the predictive capacity of the model. The $R^{2}$ value given in Table 7 is $89.66 \%$ for the mean shear strength and $90.32 \%$ for the mean adherent strength, showing good predictability of the models. ANOVA is validated by the Anderson-Darling normality test, where P-values $\geq 0.05$ (0.886 and 0.972 for shear and adherent strength, respectively) imply normal distribution data.

\subsubsection{Apparent Shear Strength}

Figure 6 shows the main effect plots for the mean apparent shear strength. The surface without wash primer reveals a $52 \%$ increase in apparent shear strength (Figure 6a). According to Oosting [28], the wash primer can improve the adhesion of the interface, but its cohesive strength is sometimes very weak, 

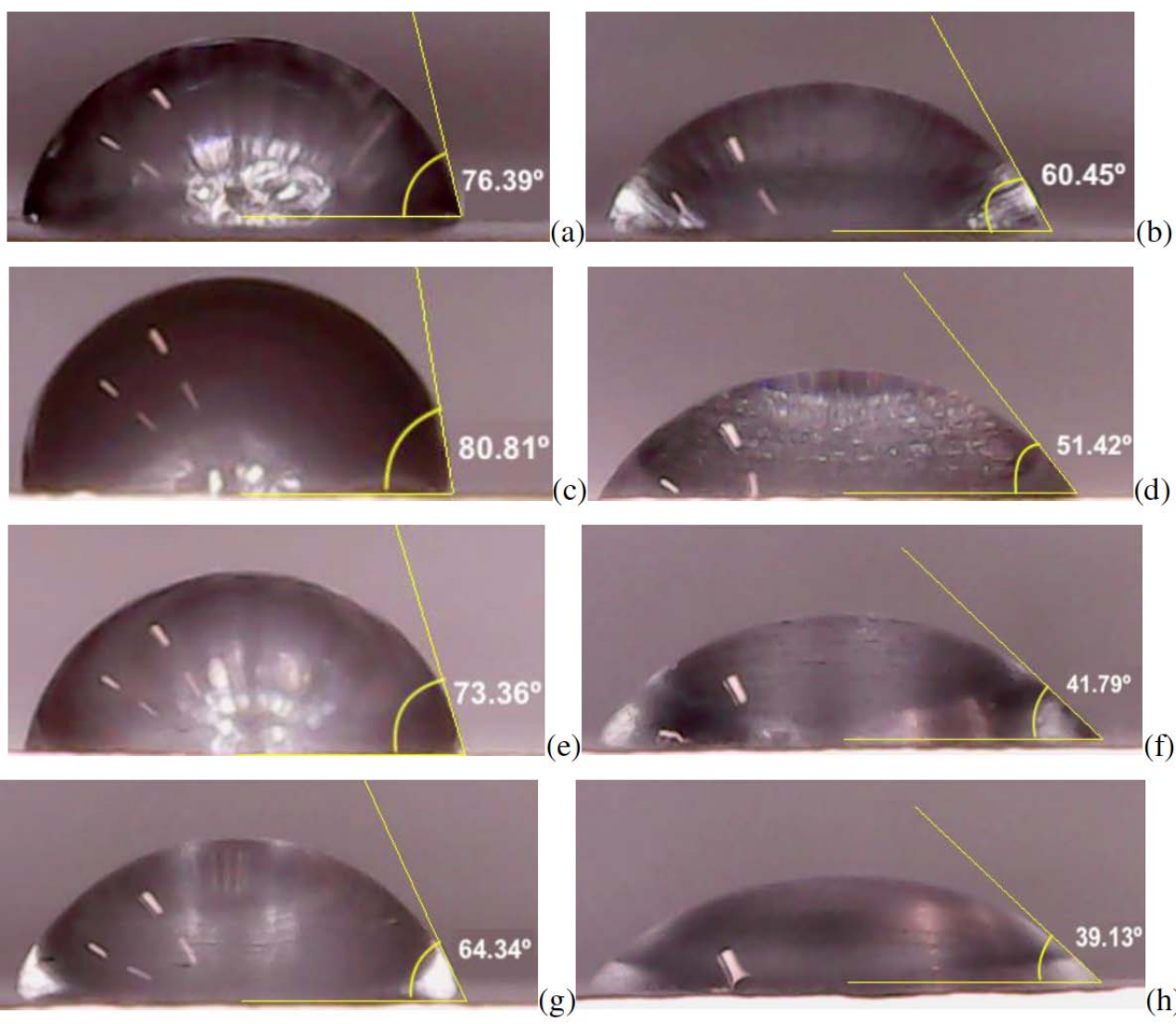

Figure 4: Contact angles for water $(\mathbf{a}, \mathbf{c}, \mathbf{e}, \mathbf{g})$ and ethilene glycol $(\mathbf{b}, \mathbf{d}, \mathbf{f}, \mathbf{h})$ drops on the degreased (a, b), mechanical abrasion (c, d), $\mathrm{NaOH} 1$ min $(\mathbf{e}, \mathbf{f})$ and $\mathrm{NaOH} 5$ min $(\mathbf{g}, \mathbf{h})$ surface treated samples.

Table 4: Contact Angle, Surface Energy and Roughness of the Treated Surfaces

\begin{tabular}{|c|c|c|c|c|c|c|}
\hline \multirow{2}{*}{ Condition } & \multicolumn{2}{|c|}{ Contact angle (deg.) } & $\begin{array}{c}\text { Dispersive } \\
\text { component }\left(\mathbf{m} / \mathbf{m}^{2}\right)\end{array}$ & $\begin{array}{c}\text { Polar component } \\
\left(\mathbf{m} J / \mathbf{m}^{2}\right)\end{array}$ & $\begin{array}{c}\text { Surface energy } \\
\left(\mathbf{m} J / \mathbf{m}^{2}\right)\end{array}$ & $\begin{array}{c}\text { Ra Roughness } \\
(\mathbf{n m})\end{array}$ \\
\cline { 2 - 6 } & Water & Ethylene Glycol & 16.80 & 28.10 & $398.4 \pm 4.4$ \\
\hline \hline Degreased & 76.39 & 60.45 & 11.30 & 6.16 & 33.67 & $501.9 \pm 8.9$ \\
\hline Abrasion & 80.81 & 51.42 & 27.51 & 9.57 & 37.63 \\
\hline NaOH 1 min. & 73.36 & 41.79 & 28.06 & 20.13 & $358.9 \pm 4.5$ \\
\hline NaOH 5 min. & 64.34 & 39.13 & 18.57 & 38.70 \\
\hline
\end{tabular}

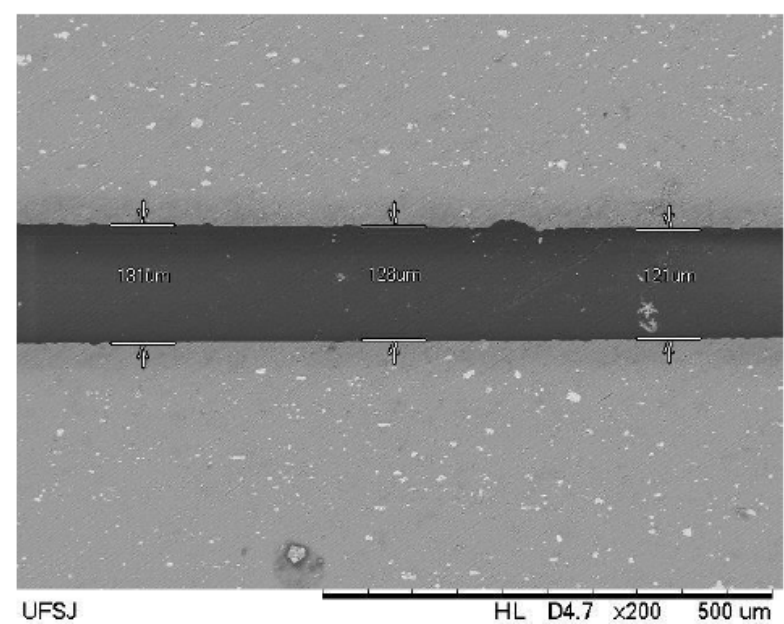

Figure 5: SEM image of the adhesive layer. 
Table 5: Descriptive Statistic for Apparent Shear Strength (MPa) Data

\begin{tabular}{|c|c|c|c|c|c|c|c|}
\hline \multicolumn{4}{|c|}{ Replicate 1} & \multicolumn{4}{|c|}{ Replicate 2} \\
\hline Setup & Mean $\pm S D$ & Setup & Mean $\pm S D$ & Setup & Mean $\pm S D$ & Setup & Mean $\pm S D$ \\
\hline C1 & $2.83 \pm 0.50$ & C9 & $3.04 \pm 0.53$ & C1 & $3.36 \pm 0.92$ & C9 & $2.95 \pm 0.48$ \\
\hline $\mathrm{C} 2$ & $3.90 \pm 0.71$ & C10 & $2.22 \pm 0.62$ & $\mathrm{C} 2$ & $5.30 \pm 0.29$ & $\mathrm{C} 10$ & $3.65 \pm 0.44$ \\
\hline $\mathrm{C} 3$ & $3.83 \pm 0.28$ & C11 & $5.85 \pm 0.77$ & $\mathrm{C} 3$ & $4.59 \pm 0.30$ & C11 & $4.91 \pm 0.60$ \\
\hline $\mathrm{C} 4$ & $5.63 \pm 0.65$ & $\mathrm{C} 12$ & $6.96 \pm 0.89$ & $\mathrm{C} 4$ & $5.58 \pm 0.47$ & $\mathrm{C} 12$ & $7.83 \pm 0.71$ \\
\hline $\mathrm{C6}$ & $5.31 \pm 0.20$ & $\mathrm{C} 14$ & $3.50 \pm 0.26$ & C6 & $3.59 \pm 0.06$ & C14 & $3.60 \pm 0.37$ \\
\hline $\mathrm{C} 7$ & $3.91 \pm 0.47$ & C15 & $4.44 \pm 0.37$ & $\mathrm{C} 7$ & $4.96 \pm 0.45$ & C15 & $5.09 \pm 0.82$ \\
\hline $\mathrm{C} 8$ & $4.06 \pm 0.58$ & C16 & $7.04 \pm 0.46$ & $\mathrm{C} 8$ & $4.80 \pm 0.69$ & C16 & $6.52 \pm 0.68$ \\
\hline
\end{tabular}

$\mathrm{SD}=$ standard deviation.

Table 6: Descriptive Statistic for Adherent Strength (N/mm) Data

\begin{tabular}{|c|c|c|c|c|c|c|c|}
\hline \multicolumn{4}{|c|}{ Replicate 1} & \multicolumn{4}{|c|}{ Replicate 2} \\
\hline Setup & Mean $\pm S D$ & Setup & Mean $\pm S D$ & Setup & Mean $\pm S D$ & Setup & Mean士SD \\
\hline $\mathrm{C} 1$ & $2707.82 \pm 173.79$ & $\mathrm{C9}$ & $2780.39 \pm 181.37$ & $\mathrm{C} 1$ & $3135.00 \pm 25.73$ & $\mathrm{C9}$ & $2320.86 \pm 196.33$ \\
\hline $\mathrm{C} 2$ & $2880.23 \pm 106.45$ & C10 & $2869.37 \pm 246.17$ & $\mathrm{C} 2$ & $3321.71 \pm 208.28$ & C10 & $2277.12 \pm 231.09$ \\
\hline C3 & $3968.01 \pm 205.71$ & C11 & $2204.56 \pm 121.43$ & $\mathrm{C} 3$ & $3774.58 \pm 93.08$ & C11 & $2138.44 \pm 99.08$ \\
\hline C4 & $4022.96 \pm 127.25$ & $\mathrm{C} 12$ & $2063.36 \pm 216.22$ & $\mathrm{C} 4$ & $3828.06 \pm 141.68$ & $\mathrm{C} 12$ & $1985.94 \pm 134.74$ \\
\hline $\mathrm{C} 6$ & $2611.20 \pm 245.81$ & C14 & $1395.98 \pm 200.69$ & C6 & $2533.89 \pm 159.32$ & C14 & $1930.73 \pm 89.84$ \\
\hline $\mathrm{C} 7$ & $1860.76 \pm 51.95$ & C15 & $2127.72 \pm 103.43$ & $\mathrm{C7}$ & $2075.12 \pm 53.21$ & C15 & $3155.29 \pm 102.26$ \\
\hline C8 & $1947.80 \pm 63.83$ & C16 & $2068.11 \pm 120.34$ & $\mathrm{C} 8$ & $1776.44 \pm 76.93$ & C16 & $1428.41 \pm 191.65$ \\
\hline
\end{tabular}

$\mathrm{SD}=$ standard deviation

Table 7: ANOVA Results

\begin{tabular}{|c|c|c|c|c|c|}
\hline & Experimental factor & \multicolumn{2}{|c|}{ Shear Strength } & \multicolumn{2}{|c|}{ Adherent Strength } \\
\hline \multirow{3}{*}{$\stackrel{\frac{.}{\pi}}{\sum}$} & Surface pre-treatment (ST) & 1.11 & 0.376 & 35.61 & $\underline{0.000}$ \\
\hline & Wash primer (WP) & 71.91 & $\underline{0.000}$ & 0.18 & 0.677 \\
\hline & Silica inclusion (SI) & 22.40 & $\underline{0.000}$ & 1.65 & 0.218 \\
\hline \multirow{4}{*}{ 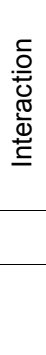 } & $\mathrm{WP} * \mathrm{SI}$ & 2.32 & 0.147 & 1.51 & 0.237 \\
\hline & $S T * W P * S I$ & 3.05 & 0.059 & 0.24 & 0.866 \\
\hline & $\mathrm{R}^{2}(\%)$ & \multicolumn{2}{|c|}{89.66} & \multicolumn{2}{|c|}{90.32} \\
\hline & $\begin{array}{c}\text { Anderson Darling } \\
\text { (P-value } \geq 0.05)\end{array}$ & \multicolumn{2}{|c|}{0.886} & \multicolumn{2}{|c|}{0.972} \\
\hline
\end{tabular}

compromising the joint strength. This fact is evidenced in Figure 7a, which presents a cohesive failure mode for the wash primer condition. Figures $\mathbf{7 b}$ and $\mathbf{7 c}$ show a combination of cohesive and adhesive failure modes of neat epoxy polymer and silica-modified epoxy polymer, respectively. The inclusion of silica leads to a 


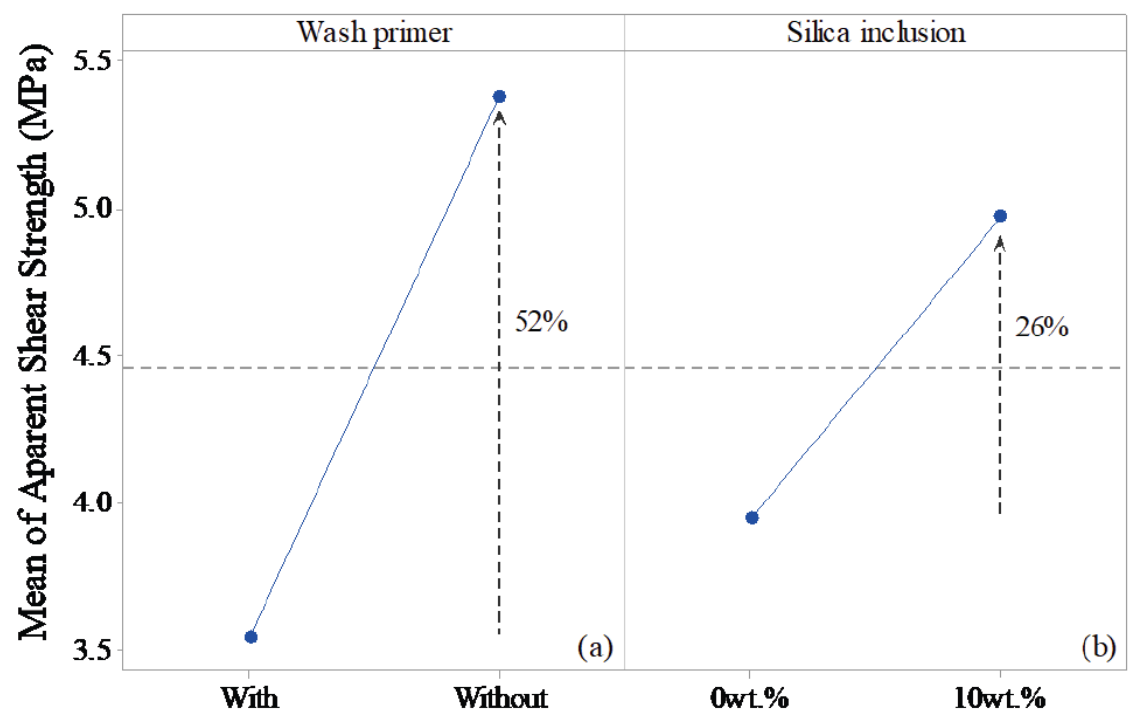

Figure 6: Main effect plots for the mean apparent shear strength.

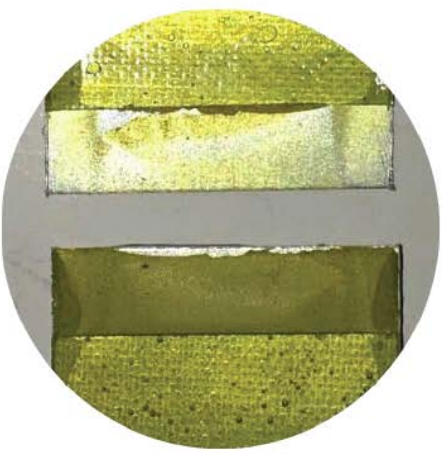

(a)

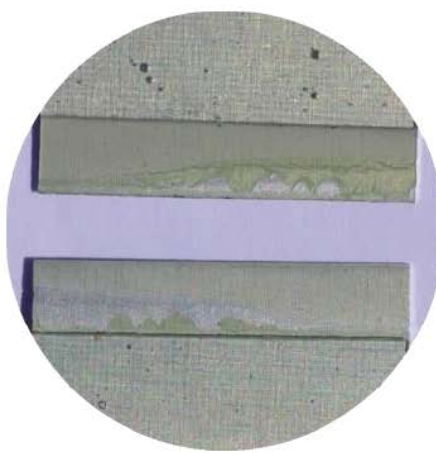

(b)

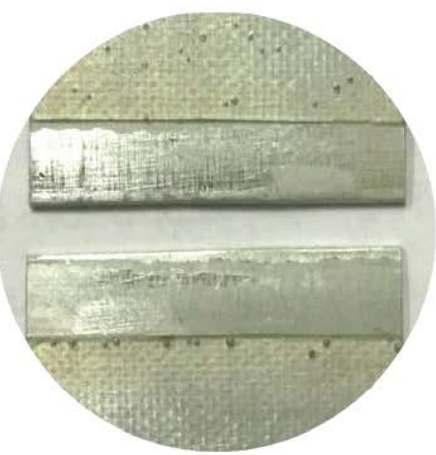

(c)

Figure 7: Failure mode of surfaces with wash primer (a), pristine epoxy adhesive (b) and silica-modified epoxy adhesive (c).

$26 \%$ increase in apparent shear strength (Figure $6 \mathbf{b}$ ). Similar results are reported by Liu et al. [26], who verified that silica inclusions can reduce crack growth rates, increasing the strength.

Figure 8 shows the interaction effect plot between the surface treatment and wash primer for the mean apparent shear strength. It is observed that all conditions without wash primer achieve greater strength. Surfaces pre-treated with $\mathrm{NaOH}$ for 1 min show a $44 \%$ increase in apparent shear strength when compared to the condition under mechanical abrasion. This is attributed to the improved infiltration of the epoxy polymer on the aluminium surface due to the higher surface energy, as shown in Table 4 . It is noteworthy that the mechanical abrasion treatment achieves the best result for wash primer-containing joints, resulting in an increase of $32 \%$ when compared to the surface treated with $\mathrm{NaOH}$ for $1 \mathrm{~min}$. This is attributed to the improved interlocking effect between the wash primer and the larger contact area provided by the greater roughness of the aluminium surface.

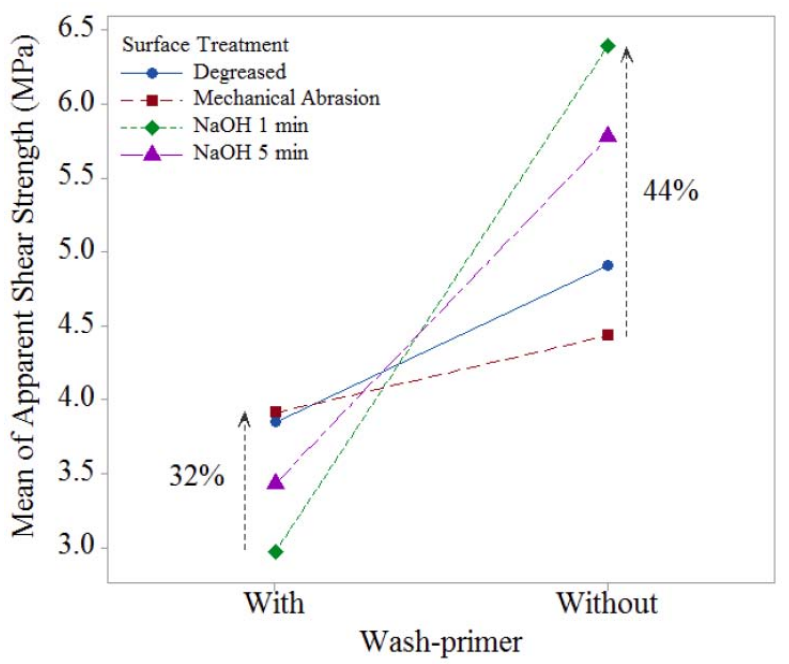

Figure 8: Interaction effect plot for the mean apparent shear strength. 


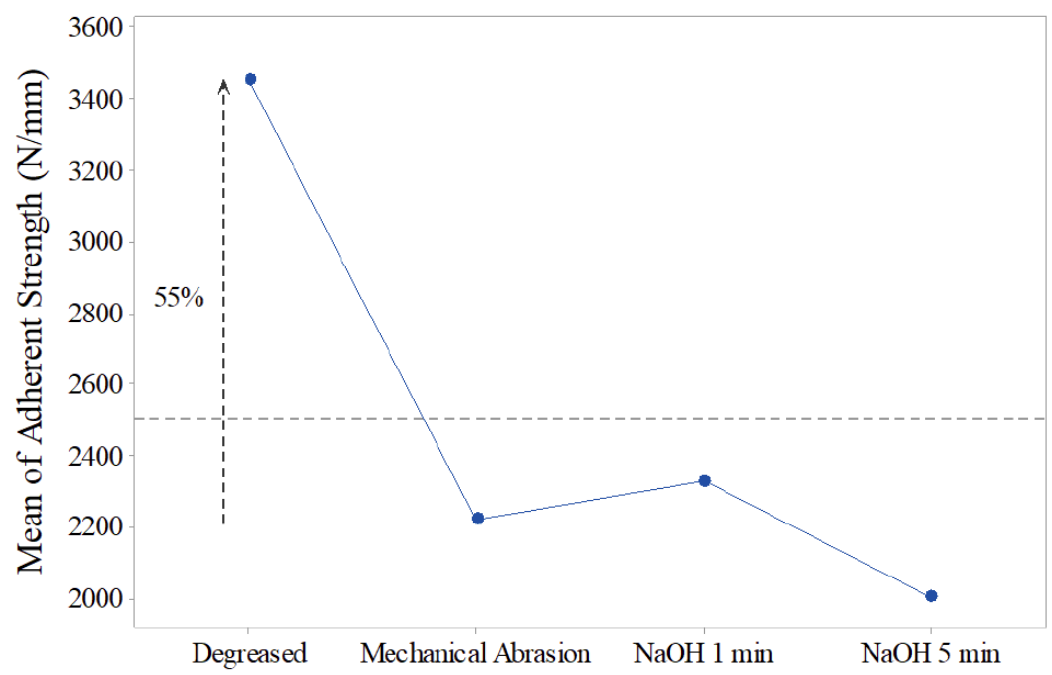

Figure 9: Main effect plot for the mean adherent strength.

\subsubsection{Adherent Strength}

Figures $\mathbf{9}$ and $\mathbf{1 0}$ show the effect plots for the mean adherent strength. The degreased surface treatment reveals a $55 \%$ increase in adherent strength (Figure 9) when compared to other conditions, while the surface treated with $\mathrm{NaOH}$ for 5 minutes exhibits the lowest strength. A different behaviour for the apparent shear strength is observed in Figure 10, in which degreased surfaces exhibit the highest results for both wash primed conditions (with and without), revealing increases of $66 \%$ and $104 \%$, respectively. While the apparent shear strength is more related to the bond strength between the interfaces, the adherent strength is related to the stiffness of this bond, since it is measured by the slope of the load versus displacement curves. Therefore, the results indicate that surface

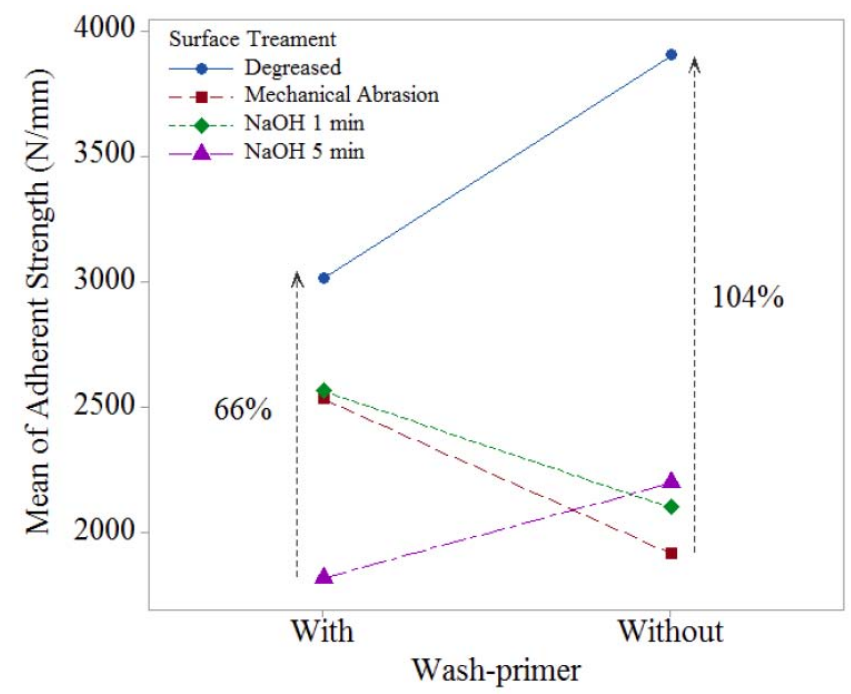

Figure 10: Interaction effect plot for the mean adherent strength. treatments on aluminium alloy 1200 , such as alkaline etching, mechanical abrasion and primer coating, compromise the bonding stiffness, while simple degreasing with neutral detergent and acetone is more effective.

\section{CONCLUSION}

The present work investigated, through statistical analysis, the effect of surface treatment, micro silica inclusions and the use of wash primer on the apparent shear strength and adherent strength of single-lap aluminium joints. Surfaces treated with alkaline solution for 5 minutes reveal the lowest contact angle in the probe's liquids and the highest surface energy, while the surface treated with mechanical abrasion presents greater roughness. The use of wash primer significantly reduces the apparent shear strength. The inclusion of $10 \mathrm{wt} . \%$ of silica particles increases the shear strength of the joints by $26 \%$. Surfaces treated with $\mathrm{NaOH}$ for one minute, without using wash primer, result in the most resistant joint. The failure mode of the joints with wash primer is mainly cohesive, while those with neat and silica-modified polymers are a combination of cohesive and adhesive. In contrast to the apparent shear strength, the adherent strength is most effective when only degreasing is considered, since this response measures the bond stiffness.

\section{ACKNOWLEDGEMENTS}

The authors would like to thank the Brazilian Research Agencies, CNPq (PQ 309885/2019-1) and FAPEMIG (PPM-00075-17) and CAPES (PhD and MSc scholarships), for the financial support provided. 


\section{REFERENCES}

[1] Sinmazçelik T, Avcu E, Bora MÖ, Çoban O. A review: Fibre metal laminates, background, bonding types and applied test methods. Mater Des 2011; 32: 3671-3685.

https://doi.org/10.1016/j.matdes.2011.03.011

[2] Dursun T, Soutis C. Recent developments in advanced aircraft aluminium alloys. Mater Des 2014; 56: 862-871. https://doi.org/10.1016/j.matdes.2013.12.002

[3] Prolongo SG, Ureña A. Effect of surface pre-treatment on the adhesive strength of epoxy-aluminium joints. Int $\mathrm{J}$ Adhes Adhes 2009; 29: 23-31. https://doi.org/10.1016/j.ijadhadh.2008.01.001

[4] Saleema N, Sarkar DK, Paynter RW, Gallant D, Eskandarian M. A simple surface treatment and characterization of AA 6061 aluminum alloy surface for adhesive bonding applications. Appl Surf Sci 2012; 261: 742-748. https://doi.org/10.1016/j.apsusc.2012.08.091

[5] Calik A. Effect of adherend shape on stress concentration reduction of adhesively bonded single lap joint. Eng Review 2016; 36: 29-43.

[6] Zhan X, Chen J, Gu C, Peng Q, Chen J, Wei Y. Study on effects of pre-treatment and surface roughness on tensileshear strength of $2060 \mathrm{Al}-\mathrm{Li}$ alloy adhesive joints. J Adhesion 2017; 93: 613-625.

https://doi.org/10.1080/00218464.2015.1124765

[7] Cen B, Liu Y, Zeng Z, Wang J, Lu X, Zhu X. Mechanical behavior of novel GFRP foam sandwich adhesive joints. Compos B Eng 2017; 130: 1-10. https://doi.org/10.1016/j.compositesb.2017.07.034

[8] Ramalho LDC, Campilho RDSG, Belinha J, da Silva LFM. Static strength prediction of adhesive joints: A review. Int J Adhes Adhes 2020; 96: 102451. https://doi.org/10.1016/j.ijadhadh.2019.102451

[9] Cui J, Wang S, Wang S, Chen S, Li G. Strength and failure analysis of adhesive single-lap joints under shear loading: Effects of surface morphologies and overlap zone parameters. J Manuf Process 2020; 56: 238-247. https://doi.org/10.1016/j.jmapro.2020.04.042

[10] Marchione F, Munafo P. Experimental strength evaluation of glass/aluminum double-lap adhesive joints. J Build Eng 2020; 30: 101284.

https://doi.org/10.1016/j.jobe.2020.101284

[11] Adibeig MR, Vakili-Tahami F, Saeimi-Sadigh M-A. Polymers 2020; 195: 122434. https://doi.org/10.1016/j.polymer.2020.122434

[12] Li W, Ghafoori E, Lu Y, Li S, Motavalli M. Analytical solution for stiffness prediction of bonded CFRP-to-steel double strap joints. Eng Struct 2018; 177: 190-197. https://doi.org/10.1016/j.engstruct.2018.09.024

[13] Sun L, Tie Y, Hou Y, Lu X, Li C. Prediction of failure behavior of adhesively bonded CFRP scarf joints using a cohesive zone model. Eng Fract Mech 2020; 228: 106897. https://doi.org/10.1016/j.engfracmech.2020.106897

[14] Xará JTS, Campilho RDSG. Strength estimation of hybrid single-L bonded joints by the eXtended Finite Element Method. Compos Struct 2018; 183: 397-406. https://doi.org/10.1016/j.compstruct.2017.04.009
[15] Carneiro MAS, Campilho RDSG, Silva FJG. Experimental and numerical analysis of adhesively-bonded $T$ joints under peel loads. Procedia Manufac 2017; 13: 51-58. https://doi.org/10.1016/j.promfg.2017.09.008

[16] Li Q, Batra RC, Graham I, Dillard DA. Examining T-peel specimen bond length effects: Experimental and numerical explorations of transitions to steady-state debonding. Inter J Solids Struct 2019; 15: 72-83. https://doi.org/10.1016/j.ijsolstr.2019.07.012

[17] Domingues NRE, Campilho RDSG, Carbas RJC, da Silva LFM. Experimental and numerical failure analysis of aluminium/composite single- $\mathrm{L}$ joints. Int $\mathrm{J}$ Adhes Adhes 2016; 64: 86-96. https://doi.org/10.1016/j.ijadhadh.2015.10.011

[18] Sorrentino L, Carrino L. 2024 aluminium alloy wettability and superficial cleaning improvement by air cold plasma treatment. J Mater Process Technol 2009; 209: 1400-1409. https://doi.org/10.1016/j.jmatprotec.2008.03.061

[19] Oliveira PR, May M, Panzera TH, Scarpa F, Hiermaier S. Reinforced biobased adhesive for eco-friendly sandwich panels. Int J Adhes Adhes 2020; 98: 102550.

https://doi.org/10.1016/j.ijadhadh.2020.102550

[20] Sapa Group (USA). Sapa Technology: Bonding of aluminum, 2016. [Online]. Available at: https://goo.gl/dNBSIO. [Accessed: 20-Jan-2021].

[21] Klomjit P, Buchheit RG. Characterization of inhibitor storage and release from commercial primers. Prog Org Coat 2018; 114: 68-77. https://doi.org/10.1016/j.porgcoat.2017.10.005

[22] Meng Q, Wang CH, Saber N, Kuan HC, Dai J, Friedrich K, Ma J. Nanosilica-toughened polymer adhesives. J Mater 2014; 61: 75-86. https://doi.org/10.1016/j.matdes.2014.04.042

[23] ASTM D1002-10, Standard Test Method for Apparent Shear Strength of Single-Lap-Joint Adhesively Bonded Metal Specimens by Tension Loading (Metal-to-Metal), 2010.

[24] Xu Y, Li H, Shen Y, Liu S, Wang W, Tao J. Improvement of adhesion performance between aluminum alloy sheet and epoxy based on anodizing technique. Int $\mathrm{J}$ Adhes Adhes 2016; 70: 74-80. https://doi.org/10.1016/j.ijadhadh.2016.05.007

[25] Santana PRT, Panzera TH, Freire RTS, Christoforo AL. Apparent shear strength of hybrid glass fibre reinforced composite joints. Polym Test 2017; 64: 307-312. https://doi.org/10.1016/j.polymertesting.2017.10.022

[26] Liu HY, Wang G, Mai YW, Cyclic fatigue crack propagation of nanoparticle modified epoxy, Compos Sci Technol 2012; 72: 1530-1538.

https://doi.org/10.1016/j.compscitech.2012.05.025

[27] Montgomery DC, Design and Analysis of Experiments, Eighth Edition. John Wiley \& Sons, Inc., 2013.

[28] Oosting R. Towards a new durable and environmentally compliant adhesive bonding process for aluminium alloys, Delft University of Technology, 1995.

https://doi.org/10.6000/1929-5995.2021.10.3

(C) 2021 Santos et al.; Licensee Lifescience Global.

This is an open access article licensed under the terms of the Creative Commons Attribution Non-Commercial License (http://creativecommons.org/licenses/by-nc/3.0/) which permits unrestricted, non-commercial use, distribution and reproduction in any medium, provided the work is properly cited. 